\title{
Evaluation of the effectiveness and safety of glucocorticoids intravitreal implant therapy in macular edema due to retinal vein occlusion
}

\section{Katarzyna Michalska- Małecka ${ }^{1,2}$ \\ Aneta Gaborek ${ }^{2}$ \\ Mariusz Nowak ${ }^{3}$ \\ Tomasz Halat ${ }^{4}$ \\ Mariola Pawłowska ${ }^{2}$ \\ Dorota Śpiewak ${ }^{2}$}

'Department of Ophthalmology, School of Medicine in Katowice, Medical University of Silesia, Katowice, ${ }^{2}$ University Center of Ophthalmology and Oncology, Independent Public Clinical Hospital, Medical University of Silesia, Katowice, ${ }^{3}$ Pathophysiology Division, Department of Pathophysiology and Endocrinology, Medical University of Silesia, School of Medicine with Division of Density, Zabrze, ${ }^{4}$ Education and Medical Simulation Center, Medical University of Silesia, Katowice, Poland
Correspondence: Katarzyna MichalskaMałecka

Department of Ophthalmology, School of Medicine in Katowice, Medical University of Silesia, Ceglana Street 35, Katowice 40-952, Poland

Tel +48 $32358 \quad 1280$

Email k.michalska.malecka@gmail.com
This article was published in the following Dove Press journal:

Clinical Interventions in Aging

23 May 2016

Number of times this article has been viewed

Abstract: The purpose of this study was to evaluate the impact of intravitreal dexamethasone implant (Ozurdex) on macular morphology and functions in eyes with macular edema (ME) secondary to retinal vein occlusion. Efficacy outcomes of the treatment were best-corrected visual acuity (BCVA) and central retinal thickness (CRT). Safety outcomes were intraocular pressure and cornea endothelial cell density. The study was conducted by the prospective analysis on 36 patients (17 women and 19 men) aged $28-77$ years (the average age was $58 \pm 15$ years) treated with the injection of dexamethasone implant because of the persistent ME at the Department of Ophthalmology and Ophthalmology Outpatient Clinic of the University Centre of Ophthalmology and Oncology in Katowice. The studied group included 16 patients with central retinal vein occlusion (16 eyes), and 20 patients with branch retinal vein occlusion (20 eyes). We found a significant increase of BCVA after first, second, and third month of treatment. Six months after the treatment, BCVA decreased, although not significantly compared with the value obtained in the third month. Two months after the intravitreal implantation of dexamethasone delivery system, CRT was $338 \pm 163$ $\mu \mathrm{m}$ and was significantly lower compared with pretreatment value. Between third and sixth month after the treatment, we found insignificant increase of CRT compared with thickness observed in second month. Two months after the treatment, we found an increase in intraocular pressure in $36 \%$ of cases and a further decrease during the final visit 6 months after the treatment. During the treatment, there were no significant differences in endothelial cell density in branch retinal vein occlusion and central retinal vein occlusion. We found the intravitreal dexamethasone implant to be safe, well tolerated, and likely to lead to fast morphological and functional improvement of the macula and visual rehabilitation in patients with ME due to retinal vein occlusion.

Keywords: macular edema, retinal vein occlusion, intravitreal implant, dexamethasone, bestcorrected visual acuity, intraocular pressure

\section{Introduction}

Retinal vein occlusion (RVO) is a sudden obstruction of the retinal venous system and it is an important cause of visual loss. ${ }^{1-3}$ There are two main types of RVO: central retinal vein occlusion (CRVO) and the branch retinal vein occlusion (BRVO), the latter being more common. Their prevalence equals to $0.6 \%-1.1 \%$ for BRVO and 0.8 per 1,000 patients for CRVO. ${ }^{4-6}$ The increase in age strongly influences the prevalence of RVO, even 5\% of people over 80 may be affected by this disease. In eyes with untreated BRVO, visual acuity may improve over time up to 20/40. ${ }^{7}$ In untreated CRVO eyes, visual acuity decreases over time. ${ }^{8}$

The pathogenesis of RVO is influenced by many factors, such as vein compression at an arteriovenous crossing, degenerative changes of vessel walls, and 
abnormal hematological and hemorheological factors may be distinguished. ${ }^{5,9-12}$ Some studies have reported connection between BRVO and higher blood viscosity due to high hematocrit and dysregulation of the thrombosis-fibrinolysis balance. ${ }^{13-16}$

BRVO as well as CRVO are frequently associated with macular edema (ME), which causes visual loss., ${ }^{2,7,8}$

The formation mechanism of ME in RVO is multifactorial and complex and embraces raised hydrostatic venous pressure, endothelial dysfunction, hypoxia degree in macula center, and inflammation and increased permeability factors in vessels like inflammatory cytokines. All these factors are responsible for the break of the blood-retina barrier due to endothelial cell dysregulation resulting in ME. . $^{3,410,17,18}$

In previous studies, the authors found that proangiogenic cytokines (vascular endothelial growth factor [VEGF] and interleukin [IL]-8) and proinflammatory cytokines (IL-6, IL-12, IL-15, IL-17, and IL-23) are elevated in the ocular fluid of the patients with BRVO or CRVO. ${ }^{19-23}$ In another study, Noma et $\mathrm{al}^{24}$ suggested that VEGF, soluble intercellular adhesion molecule-1, and IL-6 increased vascular permeability and broke the blood-retinal barrier in CRVO patients with ME.

Recently, the standard care for ME secondary to BRVO has been grid laser photocoagulation. Branch Vein Occlusion Study allowed for determination of grid laser as a standard procedure for patients with ME. ${ }^{25,26}$ Subsequent Central Vein Occlusion Study not only confirmed favorable effects of grid laser on ME but also revealed that there is no statistically important difference in visual acuity. ${ }^{25,27}$

In recent years, two novel therapies have been applied: antiinflammatory and antiangiogenic intravitreal strategies. ${ }^{28-32}$

Three anti-VEGF agents have been recognized as an effective treatment for ME in both types of RVO: intravitreal ranibizumab (Lucentis; Genentech Inc., South San Francisco, CA, USA), aflibercept (EYLEA; Bayer HealthCare, Berlin, Germany), and bevacizumab (Avastin; Genentech Inc.). Bevacizumab has been used as an off-label therapy. ${ }^{28,33-35}$

In previous studies, investigators found beneficial effects of steroids like triamcinolone acetonide, dexamethasone, and fluocinolone in edema reduction in RVO. ${ }^{31,36,37}$

In 2009, a sustained-release intravitreal $0.7 \mathrm{mg}$ dexamethasone delivery system, Ozurdex (Allergan Inc., Irvine, CA, USA), was approved for treatment of ME secondary to RVO. Ozurdex has demonstrated efficacy and safety for the treatment of BRVO and CRVO. ${ }^{30,32,38}$

Furthermore, the authors demonstrated efficacy of the dexamethasone implant in other retinal disorders associated with ME as follows: diabetic retinopathy, Irvine-Gass syndrome, noninfectious vitritis, and age-related macular degeneration. ${ }^{39-42}$

The implant is fully biodegradable, does not require surgical removal, and if necessary, it allows you to place another implant. Dexamethasone implant is applied 3-4 mm posterior to the limbus. Chang-Lin et $\mathrm{al}^{43}$ distinguished two phases of drug release. The first stage starts immediately after the implantation. It is characterized by 2-month high concentration of the drug release. After 60 days, released drug concentration decreases and the implant becomes smaller and fragmented simultaneously prolonging the therapeutic period. Within 6-month period, drug concentration declines to the nonquantifiable level.

The aim of this study was to evaluate the influence of intravitreal dexamethasone implant (Ozurdex) on macular morphology and function, and its efficacy and safety in eyes with ME secondary to RVO. Efficacy outcomes of the treatment were best-corrected visual acuity (BCVA) and central retinal thickness (CRT) and the safety outcomes were intraocular pressure (IOP) and cornea endothelial cell density (ECD).

\section{Materials and methods}

The prospective analysis was conducted on 36 patients (17 women and 19 men) aged 28-77 years (the average age was $58 \pm 15$ years) treated with the intravitreal injection of dexamethasone implant at the Department of Ophthalmology and Ophthalmology Outpatient Clinic of the University Centre of Ophthalmology and Oncology in Katowice because of ME secondary to RVO. The study was approved by Bioethical Committee of Medical University of Silesia (approval number: KNW/0022/KB1/99/II/13/14).

The group concerned included 16 patients with CRVO (16 eyes) and 20 patients with BRVO (20 eyes). The inclusion criteria for the study were: 1) decrease in BCVA using the Snellen visual acuity chart $\leq 5 / 10 ; 2$ ) CRT $>300 \mu \mathrm{m}$, as measured by optical coherence tomography (OCT); 3) IOP below $21 \mathrm{mmHg}$ (controlled by no more than one drop); 4) duration of ME shorter than 18 months; 5) age between 18 and 80 years; and 6) consent of the patient. The exclusion criteria were: 1) previous panretinal photocoagulation or pars plana vitrectomy treatment, 2) vitreous hemorrhaging, 3) aphakic eyes, 4) unregulated glaucoma or ocular hypertension, 5) active or suspected eye or eye area infections, and 6) lack of patient's consent.

Mean time of ME duration in the BRVO group was $6.50 \pm 6.50$ months (Figure 1) and in the CRVO group was 5.06 \pm 4.51 months (Figure 2). 


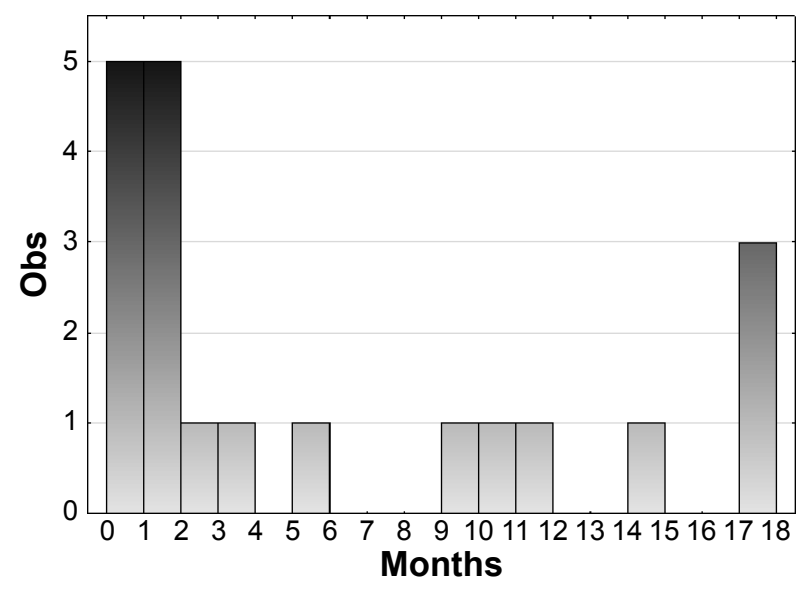

Figure I Histogram showing the distribution of the frequency of particular times of the disease in the branch retinal vein occlusion group.

Note: Obs represents the observed number of patients with branch retinal vein occlusion.

Before the intravitreal therapy, all patients underwent ophthalmic examination, which embraced: 1) BCVA using the Snellen visual acuity chart under identical testing conditions; 2) slit lamp examination including anterior and posterior segment of the eye; 3 ) morphology of the macular area accurately examined by OCT (Cirrus HD-OCT 500, Carl Zeiss Meditec AG, Jena, Germany), foveal thickness was calculated as the average retinal thickness within a circle having a $500-\mu \mathrm{m}$ radius, which was centered on the fovea; 4) IOP recording with a Goldmann applanation tonometer; and 5) ECD measured by confocal microscopy (Tomey, Erlangen-Tennenlohe, Germany).

For intravitreal therapy, $0.7 \mathrm{mg}$ dexamethasone delivery system, Ozurdex was administered 3-4 $\mathrm{mm}$ posterior to the limbus through the pars plana. The implantation was

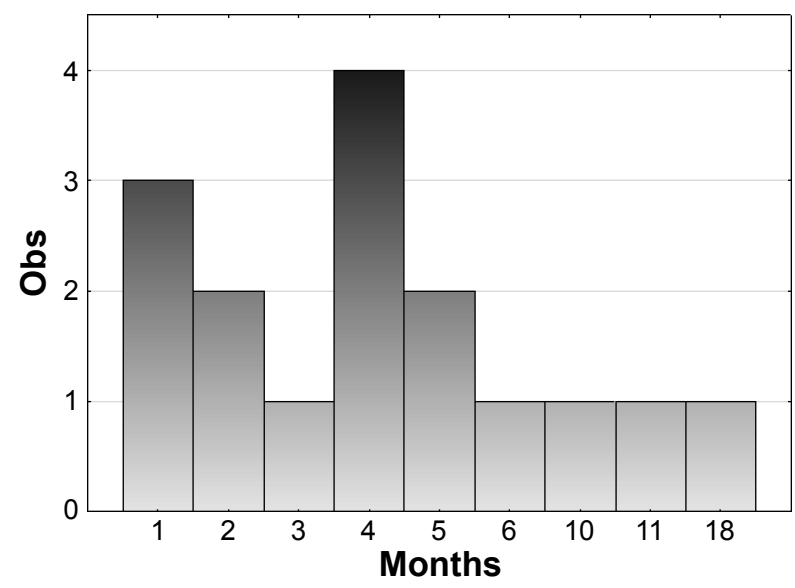

Figure 2 Histogram showing the distribution of the frequency of particular times of the disease in the central retinal vein occlusion group.

Note: Obs represents the observed number of patients with central retinal vein occlusion. performed with a sterile technique, and prophylactic topical antibiotics were applied for 1 week afterward.

According to the research report, all patients had a 6-month follow-up. Control tests were conducted 1 week, $1,2,3$, and 6 months after the treatment.

In the research, we analyzed statistical significance of differences between predrug value and subsequent values during the treatment. Because the assumption of normal population distribution (Shapiro-Wilk test) was not met, we used nonparametric Wilcoxon rank-sum test, which is an alternative to the paired Student's $t$-test. For all tests, the significance level was $\alpha=0.05$. All subjects gave a formal written consent before participating in the study. The research followed the tenets of the Declaration of Helsinki.

\section{Results}

\section{Best-corrected visual acuity}

The average pretreatment BCVA in the studied group $(n=36)$ was $0.166 \pm 0.129$, with a range of $0.002-0.500$.

For the whole group, the parametric analysis of variance tests were calculated. The statistical probability was $P=0.00504$. In order to verify which of the averages caused the existing differences, the post hoc analysis was performed. We found a significant increase of BCVA after first $(0.166 \pm 0.129$ vs $0.392 \pm 0.243, P=0.000857)$, second $(0.166 \pm 0.129$ vs $0.407 \pm 0.247, P=0.000227)$, and third $(0.166 \pm 0.129$ vs $0.320 \pm 0.249, P=0.01489)$ month of treatment. Six months after the treatment, BCVA decreased, although not significantly compared with the value obtained in the third month $(0.298 \pm 0.234$ vs $0.320 \pm 0.249$, $P=0.992626$ ) (Figure 3).

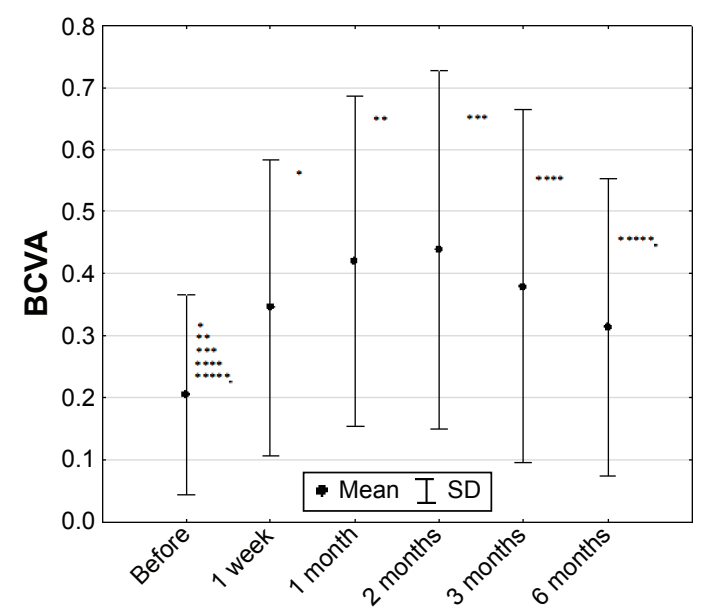

Figure 3 Best-corrected visual acuity in studied group $(n=36)$ (mean $\pm S D)$. Abbreviations: BCVA, best-corrected visual acuity; SD, standard deviation. 
In BRVO ( $0.107 \pm 0.090$ vs $0.184 \pm 0.137, P=0.02015)$ and CRVO $(0.104 \pm 0.106$ vs $0.200 \pm 0.241, P=0.04864)$ patients, a statistically significant (Friedman test) increase in BCVA values was observed after the first week of treatment. In the first and second month after the intravitreal implantation of dexamethasone delivery system, BCVA reached plateau and stayed at the similar increased level: in BRVO $(0.107 \pm 0.090$ vs $0.400 \pm 0.173, P=0.02015)$ and in CRVO $(0.104 \pm 0.106$ vs $0.235 \pm 0.281, P=0.4864)$ in first month, and in second month: in $\operatorname{BRVO}(0.107 \pm 0.090$ vs $0.410 \pm 0.094, P=0.02015)$ and in CRVO $(0.104 \pm 0.106$ vs $0.232 \pm 0.284, P=0.4864)$. In the BRVO group, plateau was maintained until the third month $(0.107 \pm 0.090$ vs $0.438 \pm 0.108, P=0.02015)$ and after 6 months it decreased $(0.107 \pm 0.090$ vs $0.337 \pm 0.152, P=0.02015)$. In the CRVO group, a decreasing tendency $(0.104 \pm 0.106$ vs $0.199 \pm 0.267, P=0.4864$ and $0.104 \pm 0.106$ vs $0.130 \pm 0.186, P=0.4864$ ) was revealed in third and sixth months, respectively after injection.

\section{Central retinal thickness}

The average preoperative CRT in the studied group was $776 \pm 301 \mu \mathrm{m}$, with a range of $427-1,362 \mu \mathrm{m}$. After the treatment, the OCT examination proved ME reduction. Two months after the intravitreal implantation of dexamethasone delivery system, CRT was $338 \pm 163 \mu \mathrm{m}$ and was significantly lower compared with pretreatment value ( $P=0.000786)$. Between third and sixth month after the treatment, we found insignificant increase of CRT compared with thickness observed in the second month $(338 \pm 163$ vs $444 \pm 206 \mu \mathrm{m}$, $P=0.1168$ in the third month and $542 \pm 182 \mu \mathrm{m}, P=0.210$ in the sixth month) (Figure 4).

Compared with measurements before injection ( $872 \pm 420 \mu \mathrm{m}$ in the BRVO group and $979 \pm 255 \mu \mathrm{m}$ in the CRVO group), foveal thickness was decreased to $347 \pm 124 \mu \mathrm{m}$ in the BRVO group $(P=0.1296)$ and $405 \pm 252 \mu \mathrm{m}$ in the CRVO group $(P=0.01945)$.

Nonparametric Friedman test results for whole group were $\chi^{2}=28.33$ and $P=0.00003$.

During the treatment, there were no significant differences (Friedman test) in the BRVO group $(P=0.12964)$. In the CRVO group, a statistically significant decrease in CRT was observed 2 months after the treatment $(978 \pm 255$ vs $405 \pm 252 \mu \mathrm{m}, P=0.01945)$. An average of $51 \%$ decrease in ME was observed 2 months after the treatment and up to $35 \%$ decrease in CRT 6 months after the treatment compared with baseline values (Figure 4).

\section{Intraocular pressure}

The average pretreatment IOP in the whole studied group was $16 \pm 3 \mathrm{mmHg}$, with a range of $11-20 \mathrm{mmHg}$. Two months after

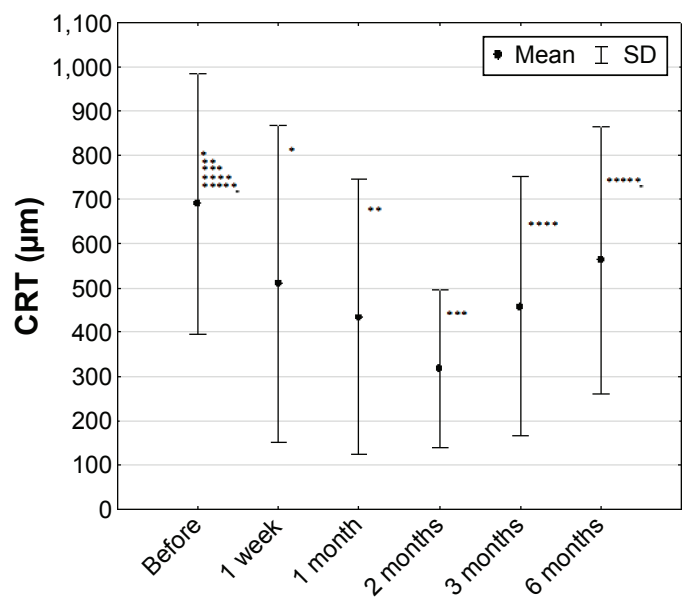

Figure 4 Central retinal thickness in studied group of patients $(n=36)$ (mean \pm SD).

Abbreviations: CRT, central retinal thickness; SD, standard deviation.

the treatment, we found an increase in IOP in $36 \%$ of cases (to the $24 \pm 7 \mathrm{mmHg}$ and further decrease to $19 \pm 5 \mathrm{mmHg}$ during the final visit 6 months after the treatment) (Figure 5). Nonparametric Friedman test results for whole group were $\chi^{2}=16.73$ and $P=0.00504$.

During the final visit, 6 months after injection of the intravitreal dexamethasone delivery system, there were no significant differences (Friedman test) of IOP in BRVO ( $17 \pm 3$ vs $17 \pm 1 \mathrm{mmHg}, P=0.13795$ ) patients compared with pretreatment measurements. In contrast, in the CRVO group we found a significant increase in IOP values compared with pretreatment value $(14 \pm 3$ vs $20 \pm 7 \mathrm{mmHg}$, $P=0.01036$ ).

Nonparametric Friedman test results for the whole group were $\chi^{2}=16.73$ and $P=0.00504$.

The most frequent complications following intravitreal implantation of Ozurdex in our study was increase of IOP

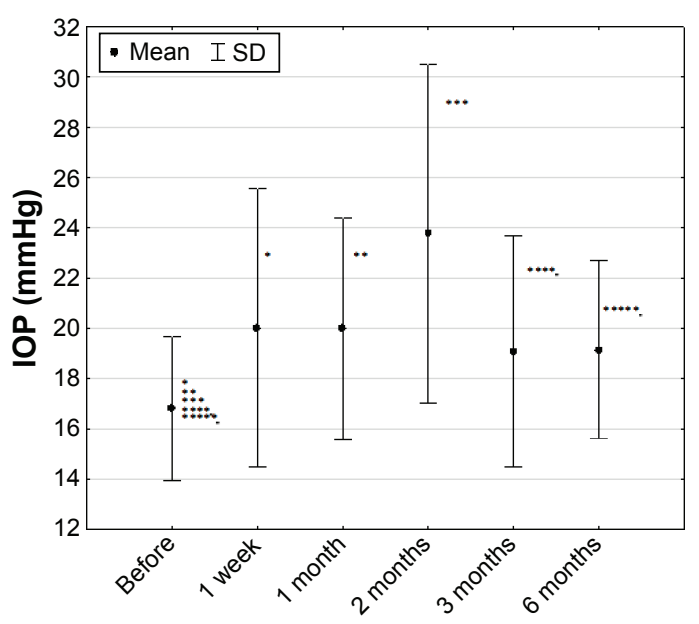

Figure 5 Intraocular pressure in studied group of patients $(n=36)$ (mean $\pm S D)$. Abbreviations: IOP, intraocular pressure; SD, standard deviation. 
observed in $36 \%$, which is comparable with the results presented by other authors. None of the patients in our study needed antiglaucoma surgery. In three cases, IOP was regulated by an application of one and in the next three cases two antiglaucomatous drops. During the final visit 6 months after the implementation, the IOP treatment was below $21 \mathrm{mmHg}$ in all patients concerned but three of them still received local antihypertonic drop treatment.

\section{Endothelial cell density}

The average ECD in the whole group was $2,154 \pm 307$ cells/ $\mathrm{mm}^{2}$ with a range of $1,704-2,718$ cells $/ \mathrm{mm}^{2}$. The parametric analysis of variance tests were performed. Statistical probability, $P=0.688715$, showed that differences between received mean values for the whole group during the time of treatment were not statistically significant (Figure 6). During the treatment, there were no significant differences (Friedman tests $)$ in $\mathrm{ECD}$ in $\mathrm{BRVO}(2,125 \pm 108, P=0.70295)$ and $\mathrm{CRVO}$ $(2,008 \pm 298, P=0.93047)$ groups either.

In our study, we found $12 \%$ of subcapsular cataract progression observed during the final visit, 6 months after the injection of Ozurdex.

\section{Discussion}

One of two most common retinal vascular disorders is RVO. Its prevalence varies from $0.7 \%$ to $1.6 \%{ }^{4,5}$

Recently, it has been shown that dexamethasone in a biodegradable drug delivery system (Ozurdex) has a positive influence on patients with RVO: it improves visual acuity as well as reduces ME..$^{40}$ Results of our study are comparable to previous studies. We have found significant functional (BCVA) and morphological (CRT) improvement of the retina

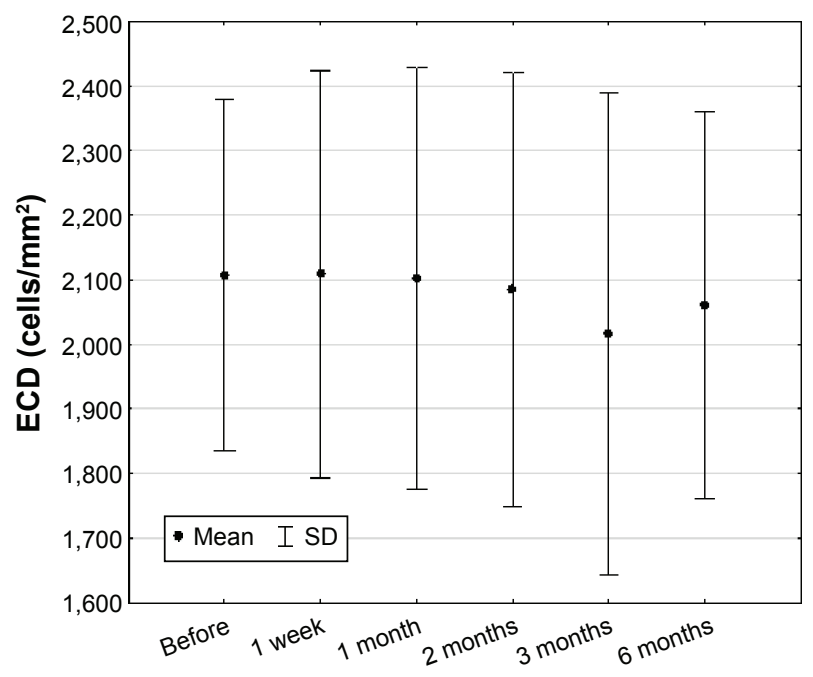

Figure 6 Endothelial cell density in studied group of patients $(n=36)$ (mean $\pm S D$ ). Abbreviations: $E C D$, endothelial cell density; SD, standard deviation. after the Ozurdex intravitreal implantation during the whole time of the observations.

Meyer and Schönfeld ${ }^{44}$ found that the dexamethasone implant had an immediate effect on ME due to RVO that set in within the first 72 hours following the intravitreal implantation of the drug, which is comparable to the results of our study. The fast effect may be explained by a relatively high concentration of dexamethasone that is released from the implant.

Use of corticosteroids including intravitreal implantation of dexamethasone may cause side effects of treatment, like posterior subcapsular cataracts, increased IOP, and the secondary ocular infections due to bacteria, fungi, or viruses.

In previous studies, which covered nearly 6,000 intravitreal injections, the authors did not observe any endophthalmitis. ${ }^{31,40}$ In accordance with the results of this study, we did not observe endophthalmitis after intravitreal Ozurdex implantation. Due to lower frequency of Ozurdex intravitreal injection when compared with anti-VEGF, the risk of endophthalmitis seems to be lower.

In SCORE (the Standard Case vs. Corticosteroid for Retinal Vein Occlusion) and GENEVA (Ozurdex GENEVA Study Group) studies, the authors found more frequent IOP elevation when compared with anti-VEGF trial. In the SCORE study, the IOP was dependent on triamcinolone dose (4 mg), with the prevalence of $41 \%$ in BRVO eyes and 35\% in CRVO eyes. ${ }^{31}$ In the GENEVA study, the authors found $25 \%$ of IOP increase 6 months after intravitreal dexamethasone implantation, ${ }^{40}$ which is also similar to the results of our study. The incidence of IOP after anti-VEGF agents was not significant as revealed by the HORIZON (Open-Label Extension Trial of Ranibizumab for Choroidal Neovascularization Secondary to Age-Related Macular Degeneration) study. ${ }^{45}$

In SCORE and GENEVA studies, a subcapsular cataract progression was observed in $20 \%-35 \%$ of patients. . $^{31,40}$ Contrary to our results, Meyer and Schönfeld ${ }^{46}$ did not notice cataract progression or increase in IOP 6 months after the intravitreal implantation of Ozurdex.

Haller et a ${ }^{30,40}$ also reported safety of retreatment with Ozurdex for RVO. The authors found the similar incidence of side effects, except for a higher frequency of cataract progression (29.8\% compared with $10.5 \%)$, and IOP elevation (15.4\% compared with $12.6 \%$ ).

The other side effects following intravitreal implantation of Ozurdex in our study were subconjunctival hemorrhage and vitreous opacity in one case. They were much less frequent and resulted from the procedure itself and the route of administration of the anticoagulant drug and were not side effects of corticosteroid. 
What is very important, in the results of our study, is the fact that the treatment had no adverse effects on the amount and function of corneal endothelial cells measured by confocal microscopy. The analysis of density of corneal endothelial cells aimed to evaluate the influence of surgical intervention (intravitreal injection) on this parameter. The analysis revealed no significant changes in ECD after the procedure giving a proof that intravitreal dexamethasone injection does not influence the cornea and, in turn, is a safe treatment method.

The ME duration seems to have an impact on the results, since our study revealed visual acuity improvement in $77 \%$ of patients with ME presence $\leq 6$ months and in only $50 \%$ of patients with ME presence 7-18 months. It is important to remember that in this disease, visual acuity is also influenced by the degree of macula ischemia, which has not been analyzed in this research.

\section{Limitation}

The limitation of this study has been its small size group; nonetheless in Polish conditions, it has been the largest conducted research analyzing the influence of dexamethasone therapy on ME due to BRVO and CRVO.

\section{Conclusion}

The dexamethasone implant (Ozurdex) may lead to fast functional improvement and visual rehabilitation in patients with ME due to RVO. The treatment is safe and well tolerated with almost no side effects. High percentage of cases with increasing IOP indicates the necessity of regular checkups of patients treated with Ozurdex.

\section{Disclosure}

The authors report no conflicts of interest in this work.

\section{References}

1. Laouri M, Chen E, Looman M, Gallagher M. The burden of disease of retinal vein occlusion: review of the literature. Eye. 2011;25(8):981-988.

2. Yau JW, Lee P, Wong TY, Best J, Jenkins A. Retinal vein occlusion: an approach to diagnosis, systemic risk factors and management. Intern Med J. 2008;38:904-910.

3. Rogers S, McIntosh RL, Cheung N, et al. The prevalence of retinal vein occlusion: pooled data from population studies from the United States, Europe, Asia and Australia. Ophthalmology. 2010;117:313-319.

4. Mitchell P, Smith W, Chang A. Prevalence and associations of retinal vein occlusion in Australia: the Blue Mountains Eye Study. Arch Ophthalmol. 1996;114:1243-1247.

5. Klein R, Klein BE, Moss SE, Meuer SM. The epidemiology of retinal vein occlusion: the Beaver Dam Eye Study. Trans Am Ophthalmol Soc. 2000;98:133-143.

6. Braithwaite T, Nanji AA, Lindsley K, Greenberg PB. Anti-vascular endothelial growth factor for macular oedema secondary to central retinal vein occlusion [Review]. The Cochrane Library. 2014;5:1-8.
7. Rogers SL, McIntosh RL, Lim L, et al. Natural history of branch retinal vein occlusion: an evidence-based systematic review. Ophthalmology. 2010;117:1094-1101.

8. McIntosh RL, Rogers SL, Lim L, et al. Natural history of central retinal vein occlusion: an evidence-based systematic review. Ophthalmology. 2010;117:1113-1123.

9. Turczyński B, Michalska-Małecka K, Słowińska L, Szczęsny S, Romaniuk W. Correlations between the severity of retinopathy in diabetic patients and whole blood and plasma viscosity. Clin Hemorheol Microcirc. 2003;29(2):129-137.

10. Rehak J, Rehak M. Branch retinal vein occlusion: pathogenesis, visual prognosis, and treatment modalities. Curr Eye Res. 2008; 33:111-131.

11. Turczyński B, Michalska-Małecka K, Słowińska L, Szczęsny S, Romaniuk W. Non-proliferative diabetic retinopathy and red blood cells aggregation. Wiad Lek. 2004;57(11-12):634-640.

12. Jefferies P, Clemett R, Day T. An anatomical study of retinal arteriovenous crossings and their role in the pathogenesis of retinal branch vein occlusions. Aust NZ J Ophthalmol. 1993;21:213-217.

13. Trope GE, Lowe GD, McArdle BM, et al. Abnormal blood viscosity and haemostasis in long-standing retinal vein occlusion. Br J Ophthalmol. $1983 ; 67: 137-142$

14. Janssen MC, den Heijer M, Cruysberg JR, Wollersheim H, Bredie SJ. Retinal vein occlusion: a form of venous thrombosis or a complication of atherosclerosis? A meta-analysis of thrombophilic factors. Thromb Haemost. 2005;93:1021-1026.

15. Turczyński B, Szyguła J, Słowińska L, Michalska-Małecka K, Drażewski R, Wodniecki J. Whole blood and serum viscosity in cardiologic X syndrome. Pol Arch Med Wewn. 2000;2(8):475-481.

16. Śpiewak D, Regucka A, Słowińska L, Kabiesz A, Witek K, MichalskaMałecka K. Changes in the hemorheological parameters in age-related macular degeneration. Okulistyka. 2014;4:38-43.

17. Campochiaro PA, Hafiz G, Shah M, et al. Ranibizumab for macular edema due to retinal vein occlusions: implication of VEGF as a critical stimulator. Mol Ther. 2008;16:791-799.

18. Chen KH, Wu CC, Roy S, Lee SM, Liu JH. Increased interleukin-6 in aqueous humor of neovascular glaucoma. Invest Ophthalmol Vis Sci. 1999;40:2627-2632.

19. Funk M, Kriechbaum K, Prager F, et al. Intraocular concentrations of growth factors and cytokines in retinal vein occlusion and the effect of therapy with bevacizumab. Invest Ophthalmol Vis Sci. 2009; 50:1025-1032.

20. Kaneda S, Miyazaki D, Sasaki S, et al. Multivariate analyses of inflammatory cytokines in eyes with branch retinal vein occlusion: relationships to bevacizumab treatment. Invest Ophthalmol Vis Sci. 2011;52: 2982-2988.

21. Noma H, Funatsu H, Yamasaki M, et al. Aqueous humour levels of cytokines are correlated to vitreous levels and severity of macular oedema in branch retinal vein occlusion. Eye (Lond). 2008;22:42-48.

22. Noma H, Minamoto A, Funatsu H, et al. Intravitreal levels of vascular endothelial growth factor and interleukin-6 are correlated with macular edema in branch retinal vein occlusion. Graefes Arch Clin Exp Ophthalmol. 2006;244:309-315.

23. Feng J, Zhao T, Zhang Y, Ma Y, Jiang Y. Differences in aqueous concentrations of cytokines in macular edema secondary to branch and central retinal vein occlusion. PLoS One. 2013;8(7):e68149.

24. Noma H, Mimura T, Tatsugawa M, Shimada K. Aqueous flare and inflammatory factors in macular edema with central retinal vein occlusion: a case series. BMC Ophthalmol. 2013;11:13-78.

25. Wong TY, Scott IU. Clinical practice. Retinal-vein occlusion. N Engl JMed. 2010;363:2135-2144.

26. Branch Vein Occlusion Study Group. Argon laser photocoagulation for macular edema in branch vein occlusion. Am J Ophthalmol. 1984; 98:271-282.

27. Central Vein Occlusion Study Group M report. Evaluation of grid pattern photocoagulation for macular edema in central vein occlusion. Ophthalmology. 1995;102:1425-1433. 
28. Brown DM, Campochiaro PA, Bhisitkul RB, et al. Sustained benefits from ranibizumab for macular edema following branch retinal vein occlusion: 12-month outcomes of a phase III study. Ophthalmology. 2011;118:1594-1602.

29. Campochiaro PA, Brown DM, Awh CC. Sustained benefits from ranibizumab for macular edema following central retinal vein occlusion: twelve-month outcomes of a phase III study. Ophthalmology. 2011;18:2041-2049.

30. Haller JA, Bandello F, Belfort R Jr, et al. Dexamethasone intravitreal implant in patients with macular edema related to branch or central retinal vein occlusion twelve-month study results. Ophthalmology. 2011;118:2453-2460.

31. Ip MS, Scott IU, VanVeldhuisen PC, et al. A randomized trial comparing the efficacy and safety of intravitreal triamcinolone with observation to treat vision loss associated with macular edema secondary to central retinal vein occlusion: the Standard Care vs Corticosteroid for Retinal Vein Occlusion (SCORE) Study report 5. Arch Ophthalmol. 2009; 127:1101-1114.

32. Kuppermann BD, Blumenkranz MS, Haller JA, et al. Randomized controlled study of an intravitreous dexamethasone drug delivery system in patients with persistent macular edema. Arch Ophthalmol. 2007; 125:309-317.

33. Brown DM, Campochiaro PA, Singh RP, et al. CRUISE Investigators: ranibizumab for macular edema following central retinal vein occlusion: six-month primary end point results of a phase III study. Ophthalmology. 2010;117:1124e1-1133e1.

34. Figueroa MS, Contreras I, Noval S, Arruabarrena C. Results of bevacizumab as the primary treatment for retinal vein occlusion. Br J Ophthalmol. 2010;94:1052-1056.

35. Pacella E, Pacella F, La Torre G, et al. Testing the effectiveness of intravitreal ranibizumab during 12 months of follow-up in venous occlusion treatment. Clin Ter. 2012;163(6):e413-e422. PMID: 23306756.

36. Jonas JB, Kreissig I, Degenring RF. Intravitreal triamcinolone acetonide as treatment of macular edema in central retinal vein occlusion. Graefes Arch Clin Exp Ophthalmol. 2002;240:782-783.
37. Jain N, Stinnett SS, Jaffe GJ. Prospective study of a fluocinolone acetonide implant for chronic macular edema from central retinal vein occlusion: thirty-six-month results. Ophthalmology. 2012;119: $132-137$.

38. Kuppermann BD, Chou C, Weinberg DV, Whitcup SM, Haller JA, Blumenkranz MS; Dexamethasone DDS Phase II Study Group. Intravitreous dexamethasone effects on different patterns of diabetic macular edema. Arch Ophthalmol. 2010;128(5):642-643.

39. Boyer DS, Faber D, Gupta S, et al; Ozurdex CHAMPLAIN Study Group. Dexamethasone intravitreal implant for treatment of diabetic macular edema in vitrectomized patients. Retina. 2011;31(5):915-923.

40. Haller JA, Bandello F, Belfort R Jr, et al; Ozurdex GENEVA Study Group. Randomized, sham-controlled trial of dexamethasone intravitreal implant in patients with macular edema due to retinal vein occlusion. Ophthalmology. 2010;117:1134-1146.

41. Pacella E, Vestri AR, Muscella R, et al. Preliminary results of an intravitreal dexamethasone implant (Ozurdex) in patients with persistent diabetic macular edema. Clin Ophthalmol. 2013;7:1423-1428.

42. Pacella E, La Torre G, Turchetti P, et al. Evaluation of efficacy dexamethasone intravitreal implant compared to treatment with antiVEGF in the treatment of diabetic macular edema. Senses Sci. 2014; 1(4):164-168.

43. Chang-Lin JE, Attar M, Acheampong A, et al. Pharmacokinetics and pharmacodynamics of a sustained-release dexamethasone intravitreal implant. Invest Ophthalmol Vis Sci. 2011;52(1):80-86.

44. Meyer LM, Schönfeld CL. Fast resolution of recurrent pronounced macular edema following intravitreal injection of dexamethasone 0.7 mg. Case Rep Ophthalmol. 2011;2(2):246-250.

45. Singer MA, Awh CC, Sadda S, et al. HORIZON: an open-label extension trial of ranibizumab for choroidal neovascularization secondary to agerelated macular degeneration. Ophthalmol. 2012;119(6):1175-1183.

46. Meyer LM, Schönfeld CL. Secondary glaucoma after intravitreal dexamethasone $0.7 \mathrm{mg}$ implant in patients with retinal vein occlusion: a one-year follow-up. J Ocul Pharmacol Ther. 2013;29(6):560-565.
Clinical Interventions in Aging

\section{Publish your work in this journal}

Clinical Interventions in Aging is an international, peer-reviewed journal focusing on evidence-based reports on the value or lack thereof of treatments intended to prevent or delay the onset of maladaptive correlates of aging in human beings. This journal is indexed on PubMed Central, MedLine,

\section{Dovepress}

CAS, Scopus and the Elsevier Bibliographic databases. The manuscript management system is completely online and includes a very quick and fair peer-review system, which is all easy to use. Visit http://www.dovepress. com/testimonials.php to read real quotes from published authors. 